\section{Structural Organization of Dental Biofilm Formed in situ in the Presence of Sucrose Associated to Maltodextrin}

\author{
Gabriela Rezende ${ }^{1}$, Rodrigo Alex Arthur ${ }^{1}$, Marcelo Lazzaron Lamers², Lina \\ Naomi Hashizume ${ }^{1}$
}

\begin{abstract}
Maltodextrins, derived from corn starch, have been added to industrialized food combined with sucrose. However it is not clear the diffusion properties of the dental biofilm matrix and the tridimensional structure of multispecies biofilms formed in the presence of these carbohydrates. Therefore, the aim of study was to investigate by confocal laser scanning microscopy (CLSM) the structural organization of the multispecies dental biofilm formed in situ under exposure to sucrose associated to maltodextrin. Adult volunteers wore an intraoral palatal appliance containing bovine enamel blocks. They were instructed to remove the appliance 8 times per day and drop the following solutions on the enamel blocks: deionized distilled water (DDW), maltodextrin, sucrose + maltodextrin or sucrose. Biofilms formed were stained and the percentage of extracellular polysaccharide (\%EPS) and thickness were determined by CLSM. Biofilm formed in the presence of sucrose and sucrose + maltodextrin presented similar \%EPS and higher than DDW and maltodextrin. Regarding to the biofilm thickness, sucrose and sucrose + maltodextrin treatments were thicker than DDW and maltodextrin and similar between them. The structural organization of the multispecies dental biofilm formed in situ in the presence of sucrose does not change when this carbohydrate is associated to maltodextrin.
\end{abstract}

'Department of Preventive and Social Dentistry, Faculty of Dentistry, UFRGS - Universidade Federal do Rio Grande do Sul, Porto Alegre, RS, Brazil ${ }^{2}$ Department of Morphological Sciences, Institute of Basic Health Sciences, UFRGS - Universidade Federal do Rio Grande do Sul, Porto Alegre, RS, Brazil

Correspondence: Lina Naom Hashizume, Rua Ramiro Barcelos, 2492, 90035-003 Porto Alegre, RS, Brasil. Tel: +55-51-3308-5348. e-mail: lhashizume@yahoo.com

Key Words: maltodextrin, sucrose, dental biofilm, dental caries, confocal laser scanning microscopy.

\section{Introduction}

Dental caries is a biofilm-dependent disease associated with frequent intake of a diet rich in rapidly fermented carbohydrates that are converted to acidic end-products by biofilm microbiota. The low $\mathrm{pH}$ induced by the fermentation of these carbohydrates disrupts the mineral equilibrium on the tooth surface, biofilm fluid, and saliva leading to tooth mineral loss (1).

It has been shown that most dietary carbohydrates, such as glucose, fructose, maltose, and sucrose, do not differ from one another regards to their acidogenic potential. This means that they are fermented at the same rate by dental biofilm bacteria (2). However, the fermentation of sucrose by Streptococcus mutans leads to the production of an insoluble form of polysaccharides that become structurally integrated into the biofilm extracellular matrix. Insoluble extracellular polysaccharides (EPS) synthesized from sucrose is able to enhance the diffusion pattern of acids throughout the biofilm matrix by increasing the porosity of the extracellular matrix. In addition, EPS acts as biological glue that enhances the adherence of microorganisms to each other and to the tooth surface, which increases dental biofilm formation. Therefore, sucrose has been considered as the most cariogenic dietary carbohydrate $(3,4)$.

Maltodextrins, which are glucose polymers obtained by hydrolysis of corn starch, have been added to industrialized food as thickening agent and to improve storage properties and texture of dry products. It is known that the caloric content of industrialized foods, such as infant formulas, dietary supplements, and sports drinks is increased by the addition of maltodextrins (5). Many maltodextrin-based products have also sucrose in the composition. In vivo studies report that the cariogenic potential of starch in association with sucrose is greater than the cariogenic potential of these carbohydrates when consumed alone $(6,7)$. Furthermore, some studies have suggested that the addition of starch would enhance the cariogenic potential of sucrose (8-10). It has also been demonstrated that soy- and milk-based infant formulas containing maltodextrins are potentially cariogenic and that their cariogenic potential increases when supplemented with sucrose (11). However a recent in vitro study investigated the effect of the association of maltodextrin and sucrose on the acidogenicity and adherence of cariogenic bacteria and reported that the addition of maltodextrin to sucrose does not increase the cariogenicity of sucrose in terms of acidogenicity and adherence of the cariogenic bacteria (12).

The cariogenic potential of dietary carbohydrates has been determined on in situ studies by traditional methods based on the quantification of tooth mineral loss and the determination of chemical composition of dental biofilms, in terms of calcium, inorganic phosphate, fluoride and EPS concentrations $(8,11)$. A recent in situ study tested if maltodextrin could increase the cariogenic potential of 
sucrose on dental enamel and concluded that the cariogenic potential of sucrose is not changed when this carbohydrate is associated to maltodextrin (13). However, it is not fully known the diffusion properties of the dental biofilm matrix and the tridimensional structure of multispecies biofilms formed in situ in response to dietary carbohydrates.

Confocal laser scanning microscopy (CLSM) allows the collection of thin serial optical sections from biological samples even in transverse planes. This method allows the evaluation of the spatial organization of biofilms through a tridimensional view of the studied samples. Based on this analysis, mixed-species in vitro biofilm formed by Streptococcus mutans, Actinomyces naeslundii and Streptococcus oralis showed that EPS may modulate the development and spatial distribution of microorganisms on biofilms as well as create micro-domains that surround micro-colonies throughout the biofilm (14). Additionally, it has been also demonstrated that the extracellular matrix of biofilms formed in vitro in the presence of sucrose associated with starch are structurally different compared with the one formed when sucrose is the sole carbohydrate (10). These aforementioned in vitro studies were conducted under strict- and well-controlled laboratory conditions using monospecies biofilms formed by $S$. mutans. Although the structure of the extracellular matrix is directly dependent on the availability of distinct dietary carbohydrates, it is important to realize that its final composition is determined by an intricate chain of microbial metabolic reactions among the biofilm counterparts that are not possible to replicate under the experimental conditions used by others $(10,14)$. Thus, it is important to evaluate the architecture of dental biofilm formed under more realistic conditions that consider both the effect of distinct sources of carbohydrates and the interactions among the microorganisms of multispecies biofilms.

This study aimed to investigate the structural organization of multispecies dental biofilm formed in situ under exposure to sucrose associated to maltodextrin by CLSM.

\section{Material and Methods}

\section{Experimental Design}

This study was an in situ, cross-over, randomized, double-blind and split-mouth study. Six adult volunteers wore during 14 days an intraoral palatal appliance containing 2 bovine enamel blocks. They were instructed to drop, 8 times per day, two of the following solutions on the enamel blocks (one solution per enamel block): deionized distilled water, maltodextrin, maltodextrin+sucrose or sucrose. After the experimental period, the biofilms formed were analyzed by CLSM. The percentage of extracellular polysaccharides (\%EPS), tridimensional structure, and thickness of the biofilm were determined. The present study randomized the distribution of enamel blocks for each intraoral appliance, the volunteers for each experimental period and the side of the intraoral appliance to apply different solutions in each experimental period. It was used the website Randomization.com (http://www. randomization.com).

\section{Subjects}

Six volunteers (aged 24.33 \pm 2.73 ) participated in this study. The inclusion criteria were as follows: good general and dental health, no receipt of antibiotics during the last 2 months, at least 24 natural teeth, unstimulated salivary flow rate of $0.25-0.35 \mathrm{~mL} / \mathrm{min}$ and no use of orthodontic appliances. The study protocol was approved by the Research and Ethics Committee of the Federal University of Rio Grande do Sul (protocol number 666.924) and informed consent was obtained from each participant prior to the beginning of the study.

\section{Enamel Blocks and Palatal Appliance Preparation}

Enamel blocks were obtained from bovine incisors previously stored on $2 \%$ buffered formaldehyde solution (pH 7.0) during 30 days. Teeth presenting fractures on the external enamel surface, as well as any cracks were excluded. Twenty-four enamel blocks $(3 \times 3 \times 2 \mathrm{~mm})$ with flat and polished surfaces were prepared from these teeth.

Acrylic resin intraoral palatal appliances containing two cavities, one at each side, were made for each volunteer. One enamel block was placed on each cavity and covered by a plastic mesh leaving $1.0 \mathrm{~mm}$ space for biofilm accumulation. Plastic meshes were fixed with colorless or red color acrylic resin to help the volunteer to identify where each solution should be dropped (8).

\section{Solutions}

The tested solutions were: distilled and deionized water (DDW), 10\% sucrose (S) (Synth, Diadema, SP, Brazil), 10\% maltodextrin (M) (DE 13-17, Sigma-Aldrich, St. Louis, MO, EUA) and 10\% sucrose $+10 \%$ maltodextrin $(\mathrm{S}+\mathrm{M})$. We used the concentration $10 \%$ maltodextrin because this is the approximately the concentration found in industrialized foods containing maltodextrin. The concentration 10\% sucrose was used based on several studies about cariogenicity in dental biofilm $(8,15)$. Concentrations were calculated by weight/volume. New solutions were provided to the volunteers every three days, in milky white bottles identified with a white or red label. Two tested solutions were used by each volunteer at each experimental period considering a split-mouth design as follow: DDW and S or M and S+M. The use of the two treatments on the same intra-oral appliance (split-mouth) 
is supported by previous studies demonstrating an absence of cross effect $(8,16)$. Considering a cross-over design, all subjects were submitted to all tested treatments. The volunteers were instructed to remove the appliance from the mouth and drip one drop of the assigned solution on each enamel block, 8 times a day, at pre-determined times (8:00, 9:30, 11:00, 13:30, 15:00, 16:30, 18:00 and 21:00). Five minutes after the solution has been dripped, the excess of solution on the appliance was dried with gauze and the appliance was put back into the mouth. Volunteers were instructed to use the appliance at all times, removing it only for the intake of food and drinks and to realize oral hygiene. No restriction were made in diet and for the entire period the volunteers used fluoridated water $(0.8 \mathrm{ppmF})$ and non-fluoridated toothpaste, provided by the researchers. A seven-day washout period was performed previously to the beginning of the first experimental phase and between the two experimental phases.

\section{Confocal Laser Scanning Microscopy and Image Analysis}

At the end of the experimental phase, all samples were numerically codified unable any identification of treatment group. The enamel blocks/biofilms were then aseptically and individually transferred to a 24-well plate. Biofilms were fixed with 4\% paraformaldehyde for $60 \mathrm{~min}$ and immersed in lysozyme solution $(70,000 \mathrm{U} / \mathrm{mL}$ in Tris/HCl pH 7.5, $5 \mathrm{mM}$ EDTA) for 7 min at $37^{\circ} \mathrm{C}$ to allow the permeabilization of gram-positive bacteria. Biofilms were stained by immersion in $0.3 \%$ SYTO 9 (Invitrogen, Carlsbad, CA, USA) for $30 \mathrm{~min}$ at room temperature. The extracellular polysaccharides (EPS) of biofilm matrix was stained by immersion in Calcofluor (Sigma-Aldrich, Poole, Dorset, UK; $10 \mathrm{ug} / \mathrm{mL}$ solution in $10 \mathrm{mM}$ sodium phosphate $\mathrm{pH}$ 7.5) for $60 \mathrm{~min}$ at room temperature. Biofilms were then immersed upside down in $20 \mu \mathrm{L}$ of Mowiol and stored at room temperature in the dark for at least $6 \mathrm{~h}$ prior to microscopic examination (17).

Biofilms were analyzed using an inverted confocal microscope FV-1000-PME (Olympus, Shinjuku, Tokyo, Japan), with UV laser (Coherent Inc., Santa Clara, CA, USA) He-Ne (Uniphase Vertriebs GmbH, Eching, Munich, Germany) and $\operatorname{Ar}$ (Coherent Inc.) and a confocal laser were operated by a computer. Filters were set to $400-490 \mathrm{~nm}$ for detection of Calcofluor and 520-540 nm for detection of SYTO 9. Confocal images were obtained using objective 40x (numeric aperture 1.25) and 100x (numeric aperture 1.4) of 3 randomly selected regions were imaged for each biofilm. Images were acquired in a standardized way for all samples. Initially, an image was acquired from the center of each sample and then from 2 opposite points close to the center region. Vertical sections of approximately 0.44 $\mathrm{mm}$ thickness were obtained for each field.
The images were exported to Image J software (National Institutes of Health, Montgomery, MD, USA) in which analysis was performed by calculating the area occupied by the green and blue dyes (SYTO 9 and Calcofluor, respectively) in each sample. The average of the areas occupied by SYTO 9 (biofilm bacteria) and Calcofluor (extracellular matrix of the biofilm) for each sample was also calculated. The thickness of the biofilm was determined for each of the three areas and averaged to calculate the mean thickness of the biofilms. In order to analyze the homogeneity of the biofilm, the Z-stack obtained from the confocal analysis of Calcofluor was submitted to a reconstruction of the biofilm organization and a densitometry map using the $3 \mathrm{D}$ viewer plugin for the Image J software. All procedures (from image acquisition to image analysis) were made by a blind examiner who was unable to identify the treatment groups. Sample identification codes were broken only after all samples have been analyzed.

\section{Data Analysis}

The data of biofilm thickness and percentage of EPS on each of the tested conditions were subjected to a one-way ANOVA. The assumptions of normal distribution of error and equality of variance and were checked for both response variables by Shapiro-Wilk test and Levene's test, respectively. Comparison among the different carbohydrates solutions was then made using an LSD test. SPSS software (Statistical Package for Social Sciences - IBM, Armonk, NY, USA) version 21.0 for Windows was used for statistical analysis at the level of significance of $5 \%$.

\section{Results}

Representative images of biofilms formed under the tested conditions are shown in Figure 1 generated by the $3 \mathrm{D}$ viewer. No difference was found between $\mathrm{S}$ and $\mathrm{S}+\mathrm{M}$, however a higher \%EPS was observed when compared with DDW and M (Table 1). Biofilms formed in the presence of $\mathrm{S}$ and $\mathrm{S}+\mathrm{M}$ did not differ in thickness but were thicker than biofilms formed in the presence of DDW and $M$, which were similar between them. Differences in thickness of biofilms among the experimental conditions are also shown in Figure 1.

The qualitative analysis of the $3 \mathrm{D}$ reconstruction of the biofilm associated to a densitometry map of the fluorescence signal demonstrated that water and maltodextrin produced thin biofilms with low amounts of extracellular matrix. On the other hand, S and S+M produced thicker and more porous biofilms which presented a higher signal for the deposition of EPS (Fig. 1).

\section{Discussion}

The biofilms formed in this study showed considerable 
heterogeneity regarding thickness, distribution of cells, and $\%$ EPS. Higher \%EPS was observed for biofilms formed in the presence of $\mathrm{S}$ and $\mathrm{S}+\mathrm{M}$ (Table 1, Fig. 1). These results are in agreement with in vitro studies that showed an increased amount of EPS on S. mutans monospecies biofilms (14) and on defined mixed-species biofilms $(14,18)$ both formed in the presence of sucrose.

It has been shown that microenvironments are created on biofilms owing to the presence of EPS on the biofilm matrix. EPS helps to create spatial heterogeneities on biofilms by forming EPS-enmeshed bacterial islets that create acidic pockets on biofilms by impeding neutralization by salivary buffer. Additionally, biofilms formed under this condition are more resistant to the antimicrobial effect of chlorhexidine (14). EPS also play a role in increasing biofilm adherence to tooth surfaces. Studies have suggested that once EPS is synthesized, it can adhere to cell surface receptors, such as glucanbinding proteins, and act as biological glues allowing co-aggregation among different microbial species $(3,19)$. EPS can attach to the tooth surface as part of the salivary pellicle. This also allows bacterial attachment and biofilm formation (19). Clinical studies have also suggested a positive correlation between the concentration of EPS on multispecies in vivo dental biofilms and the caries status of young children $(20,21)$.

In situ studies have shown that biofilms formed in the presence of sucrose have an increased cariogenic potential. Enamel mineral loss in the presence of sucrose can be 2-fold greater than that in the presence of glucose and fructose, which are not substrates for the synthesis of EPS (22). It has been discussed that when comparing biofilms formed only in the presence of sucrose, EPS formed in the

Table 1. Percentage of extracellular polysaccharides (\%EPS) and thickness (mean \pm SD) of the biofilms per subject $(\mathrm{n}=6)$ according to the experimental conditions.

\begin{tabular}{lcccc}
\hline \multirow{2}{*}{ Variable } & \multicolumn{4}{c}{ Treatments } \\
\cline { 2 - 5 } & DDW & Maltodextrin & Sucrose & $\begin{array}{c}\text { Sucrose }+ \\
\text { Maltodextrin }\end{array}$ \\
\hline \%EPS & $25.83 \pm 4.17^{\mathrm{A}}$ & $23.06 \pm 3.61^{\mathrm{A}}$ & $45.63 \pm 12.98^{\mathrm{B}}$ & $41.85 \pm 10.13^{\mathrm{B}}$ \\
Thickness $(\mu \mathrm{m})$ & $56.92 \pm 18.60^{\mathrm{A}}$ & $42.5 \pm 2.92^{\mathrm{A}}$ & $84.7 \pm 15.40^{\mathrm{B}}$ & $106.8 \pm 14.40^{\mathrm{B}}$ \\
\hline
\end{tabular}

EPS $=$ extracellular polysaccharides. Distinct capital letters show statistically significant differences, ANOVA followed by LSD test $(\mathrm{p}<0.05)$

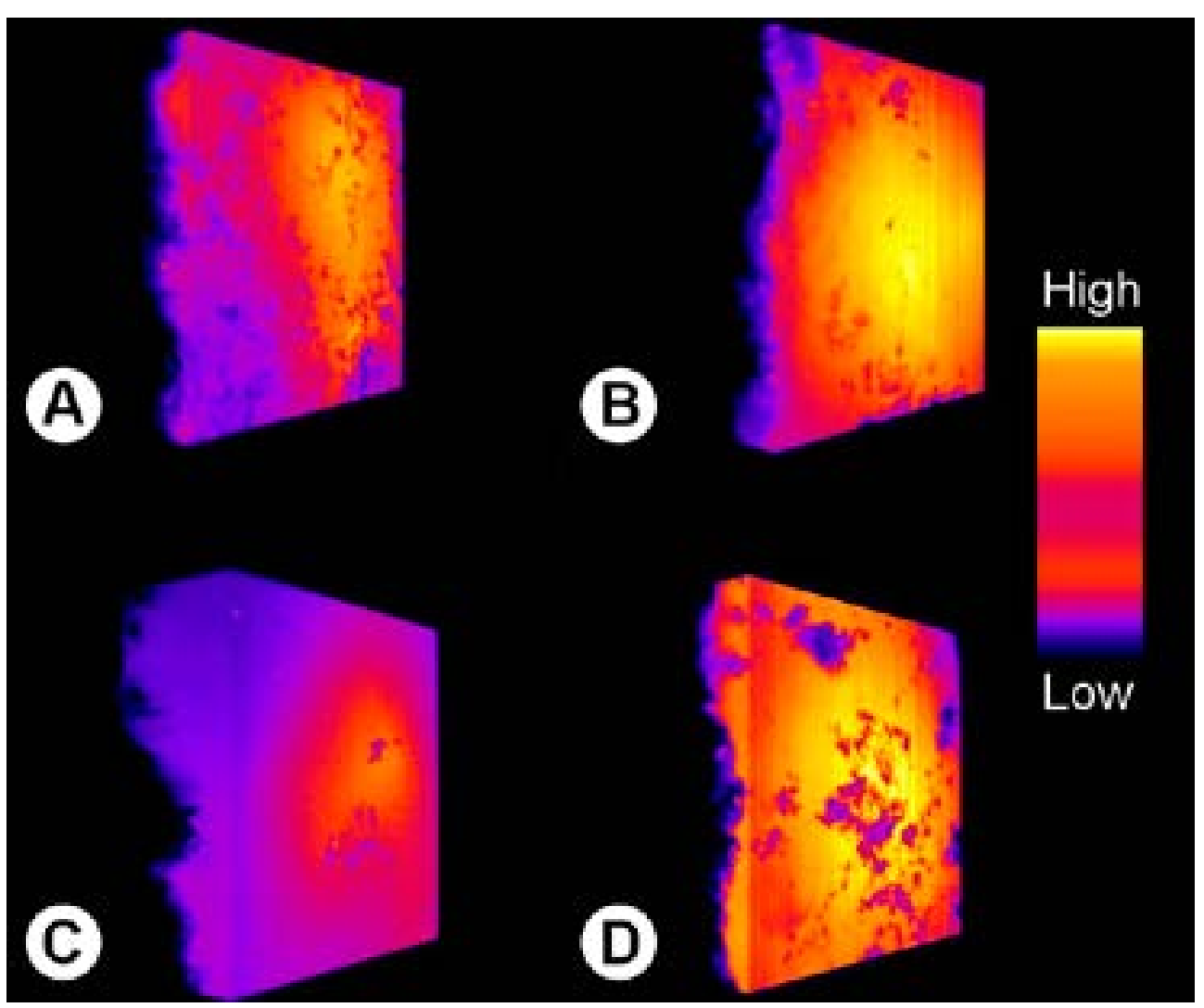

Figure 1. Representative images of biofilms formed under different treatments by 3D viewer. A - Distilled and deionized water; B - Sucrose; C Maltodextrin; D - Sucrose + maltodextrin. Densitometry map (right) represents the fluorescence intensity for Calcofluor, a marker for extracellular polysaccharides. 
presence of starch and sucrose produces higher amounts of a1-3 linkages that increase their insolubility (9). Besides, EPS formed in the presence of this association is able to alter the structural organization of the extracellular matrix (10). Consequently, the cariogenic potential of multispecies biofilm formed in situ in the presence of starch and sucrose increases since the area of the carious lesion is about 1.5fold greater than the biofilms formed only in the presence of sucrose (8).

The food industry is increasingly using maltodextrin in their products, and often it is associated with sucrose. Our data suggest that the use of maltodextrin as a sole carbohydrate does not alter the structural organization of multispecies biofilms formed in situ in comparison with those formed in the presence of water (negative control) (Table 1, Fig. 1). Previous study showed that maltodextrin has lower fermentation rate compared to glucose by cariogenic bacteria. In terms of microbial adherence, the percentage of adherent cells of $S$. mutans is significantly lower in presence of maltodextrin in comparison to other carbohydrates (12). We hypothesize tough that in situ multispecies biofilms are not able to synthesize EPS using maltodextrin as substrates, as indicated by the higher proportion of cells and lower proportion of EPS in comparison with biofilms formed in the presence of sucrose (Table 1). Considering the direct association between EPS and caries development (4), it might be possible that biofilms formed in the presence of maltodextrin present lower cariogenic potential in comparison with those formed in the presence of sucrose.

Previous in situ study observed that the cariogenic potential of sucrose associated with maltodextrin on dental enamel and concluded that the cariogenic potential of sucrose is not changed when this carbohydrate is associated to maltodextrin (13). In the present study, the addition of maltodextrin to sucrose did not show different results compared to sucrose alone. The structures of multispecies biofilms formed in situ in the presence of sucrose associated to maltodextrin were similar. This could also indicate a similar cariogenic potential between sucrose alone and sucrose associated to maltodextrin in agreement with the previous study. However, it is possible that the EPS synthesized in the presence of sucrose associated to maltodextrin is different compared with that synthesized only in the presence of sucrose, as has been previously described for $S$. mutans monospecies biofilms formed in the presence of the association between starch and sucrose (9). Our data do not allow any conclusions to be made in this regard, but this point deserves further investigation to elucidate the chemical composition of EPS synthesized under these conditions.

In addition, our results suggest that \%EPS is directly related to the thickness of multispecies biofilms. As shown previously, biofilms formed in the presence of sucrose were denser and thicker than the biofilms formed in the absence of this carbohydrate (23). It has been discussed that the increase in thickness may be related to the increase in biofilm matrix porosity induced by the presence of EPS synthesized from sucrose. A more porous biofilm allows greater diffusion of substrates across the biofilm, promoting increased metabolism and acid production by the microorganisms located at tooth/biofilm interface (24). Based on these observations, analysis of dental biofilm by tridimensional reconstruction using CLSM is a promising methodology because it allows a better visualization of these pores. The present study is the first to use this methodology to do a qualitative and quantitative analysis for investigating the cariogenic potential of multispecies dental biofilm.

It is important to point out that the difference in the number of captured images among the experimental groups is due to sample preparation. All six subjects used the tested solutions, but during the preparation of samples for CLSM, biofilm samples of $M$ and $M+S$ from five subjects and biofilm samples of DDW and $\mathrm{S}$ from 2 subjects detached from the enamel surface during fixation/ treatment with lysozyme solution. This is the reason 3 images were captured from $M$ and $M+S$ whereas 12 images were captured in total (3 per subject) for DDW and S samples. Even though presenting differences in sample size, it was possible to show that the exposure to sucrose during biofilm formation $(\mathrm{S}$ and $\mathrm{M}+\mathrm{S}$ groups) increased both the \%EPS and thickness of biofilms. This suggests that our results are clinically relevant and they are in agreement with those previously reported by other authors $(8,14)$, irrespective to the number of scanned biofilm areas. This way, any bias that may have been induced by different sample size among the experimental groups was downgraded.

Additionally, although the total carbohydrate amount of $10 \%$ sucrose $+10 \%$ maltodextrin solution had been higher than their respective counterpart solutions (10\% sucrose or 10\% maltodextrin), we may suggest that this difference on carbohydrate amount did not significantly affect the results of our study. Aires et al., who evaluated in situ the cariogenic potential of solutions containing $2 \%$ starch, 10\% sucrose and the association of 2\% starch $+10 \%$ sucrose against root dentine, also found similar cariogenic potential between 10\% sucrose and the association of $2 \%$ starch $+10 \%$ sucrose solutions irrespective to their carbohydrate amount, in agreement with the results of the present study (15).

Calcofluor dye is a universal polysaccharide stain. So it may bind unselectively to all extracellular polysaccharides of biofilm matrix, and not only to insoluble EPS which are 
considered the key-factor for the development of cariogenic biofilms (19). One could argue, then, this represents a limitation for the use of CLSM, since it might be possible that the determination of $\%$ of insoluble EPS has been overestimated. Alternatively, colorimetric and biochemical methods have been extensively used to precisely quantify insoluble EPS on biofilm matrix $(8,13,15,21,22,25)$. However, it is important to emphasize that the present data of $\%$ stained EPS and the differences among the experimental groups represents those differences previously found based on biochemical and colorimetric determination of insoluble EPS on biofilms formed under the same conditions described in this study (13), suggesting that calcofluor and CLSM may also be used for the purpose of estimating insoluble EPS on biofilms. Moreover, our study also shows that thickness of biofilms corresponds to the increase on EPS, which has been clinically showed by others $(26,27)$.

CLSM was found to be effective tool for investigating the structure of multispecies dental biofilm. It was possible to show that the structural organization of biofilms is directly dependent on the availability and source of carbohydrate during biofilm formation. Multispecies biofilms formed in the presence of sucrose or sucrose associated to maltodextrin have higher \%EPS and thickness compared to those formed in the presence of maltodextrin alone. The structural organization of the multispecies biofilm formed in situ in presence of sucrose does not change when this carbohydrate is associated to maltodextrin.

\section{Resumo}

Maltodextrinas, derivadas do amido de milho, tem sido adicionadas a alimentos industrializados combinadas à sacarose. Entretanto não estão esclarecidas as propriedades de difusão na matriz do biofilme dental e a estrutura tridimensional de biofilmes multiespécies formados na presença destes carboidratos. Portanto o objetivo deste estudo foi avaliar, através da microscopia confocal de escaneamento a laser (MCEL), a organização estrutural do biofilme dentário multiespécie formado in situ exposto à sacarose associada a maltodextrina. Voluntários adultos utilizaram dispositivos intraorais palatinos contendo blocos de esmalte bovino. Eles foram instruidos a remover os dispositivos 8 vezes por dia e gotejar as seguintes soluções sobre os blocos de esmalte: água destilada e deionizada (ADD), maltodextrina, sacarose+maltodextrina ou sacarose. Os biofilmes formados foram corados e o percentual de polissacarideos extracelulares (\%PEC) e suas espessuras foram determinados através da MCEL. Os biofilmes formados na presença de sacarose e sacarose+maltodextrina apresentaram os \%PEC similares entre si, entretanto maiores do que os grupos submetidos a ADD e maltodextrina. Em relação à espessura do biofilme formado, os tratamentos sacarose e sacarose+maltodextrina apresentaram espessuras similares entre si, e maiores quando comparados aos grupos ADD e maltodextrina. A organização estrutural do biofilme dentário multiespécie formado in situ na presença de sacarose não é alterado quando este carbiodrato é associado a maltodextrina.

\section{References}

1. Marsh PD. Are dental diseases examples of ecological catastrophes? Microbiol 2003;149:279-294.

2. Koulourides T, Bodden S, Keller S, Manson-Hing L, Lastra J,Housch T. Cariogenicity of nine sugars tested with an intraoral device in man.
Caries Res 1976;10:427-441.

3. Rölla G. Why is sucrose so cariogenic? The role of glucosyltransferase and polysaccharide. Scand J Dent Res 1989;97:115-119.

4. Paes Leme AF, Koo H, Bellato CM, Bedi G, Cury JA. The role of sucrose in cariogenic dental biofilm formation - new insight. J Dent Res 2006;85:878-887.

5. Grenby TH, Mistry M. Properties of maltodextrins and glucose syrups in experiments in vitro and in the diets of laboratory animals, relating to dental health. Br J Nutr 2000;84:565-574.

6. Firestone AR, Shmid R, Muhlemann HR. Cariogenic effects of cooked wheat starch alone or with sucrose and frequency-controlled feedings in rats. Arch Oral Biol 1982;27:759-763.

7. Thurnheer T, Giertsen E, Gmür R, Guggenheim B. Cariogenicity of soluble starch in oral in vitro biofilm and experimental rat caries studies: a comparison. J Appl Microbiol 2008;105:829-836.

8. Ribeiro CC, Tabchoury CP, Del Bel Cury AA, Tenuta LM, Rosalen PL, Cury JA. Effect of starch on the cariogenic potential of sucrose. Br J Nutr 2005;94:44-50.

9. Duarte S, Klein MI, Aires CP, Cury JA, Bowen WH, Koo H. Influences of starch and sucrose on Streptococcus mutans biofilms. Oral Microbiol Immunol 2008;23:206-212.

10. Klein MI, Duarte S, Xiao J, Mitra S, Foster TH, Koo H. Structural and molecular basis of the role of starch and sucrose in Streptococcus mutans biofilm development. Appl Environ Microbiol 2009;75:837841.

11. de Mazer Papa AM, Tabchoury CP, Del Bel Cury AA, Tenuta LM, Arthur RA, Cury JA. Effect of milk and soy-based infant formulas on in situ demineralization of human primary enamel. Pediatr Dent 2010;32:3540.

12. Stegues CG, Arthur RA, Hashizume LN. Effect of the association of maltodextrin and sucrose on the acidogenicity and adherence of cariogenic bacteria. Arch Oral Biol 2016;65:72-76.

13. Rezende G, Grando D, Arthur RA, Hashizume LN. Cariogenic potential of sucrose associated with maltodextrin on dental enamel. Caries Res 2017:51:129-135.

14. Xiao J, Klein MI, Falsetta ML, Lu B, Delahunty CM, Yates JR, et al. The exopolysaccharide matrix modulates the interaction between $3 \mathrm{D}$ architecture and virulence of a mixed-species oral biofilm. PLoS Pathog 2012;8: e1002623.

15. Aires $C P$, Del Bel Cury AA, Tenuta LM, Klein, MI, Koo H, Duarte $S$, et al. Effect of starch and sucrose on dental biofilm formation and on root dentine demineralization. Caries Res 2008;42:380-338.

16. Hara AT, Queiroz CS, Paes Leme AF, Serra MC, Cury JA. Caries progression and inhibition in human and bovine root dentine in situ. Caries Res 2003;37:339-344.

17. Thurnheer $T, G$ mür $R$, Shapiro $S$, Guggenheim B. Mass transport of macromolecules within an in vitro model of supragingival plaque. Appl Environ Microbiol 2003;69:1702-1709.

18. Koo H, Xiao J, Klein MI, Jeon JG. Exopolyssacharides produced by Streptococcus mutans glucosyltransferases modulate the establishment of microcolonies within multispecies biofilms. J Bacteriol 2010;192:3024-3032.

19. Bowen WH, Koo H. Biology of Streptococcus mutans derived glucosyltransferases role in extracellular matrix formation of cariogenic biofilms. Caries Res 2011;45:69-86.

20. Mattos-Graner RO, Smith DJ, King WF, Mayer MPA. Water-insoluble Glucan synthesis by Mutans Streptococcal Strains Correlates with Caries Incidence in 12- to 30-month-old Children. J Dent Res 2000;79:1371-1377.

21. Nobre dos Santos M, Melo dos Santos L, Francisco SB, Cury JA. Relationship among dental plaque composition, daily sugar exposure and caries in the primary dentition. Caries Res 2002;36:347-352.

22. Cury JA, Rebelo MA, Del Bel Cury AA, Derbyshire MT, Tabchoury $\mathrm{CP}$. Biochemical composition and cariogenicity of dental plaque formed in the presence of sucrose or glucose and fructose. Caries Res 2000;34:491-497.

23. Singleton $S$, Treloar $R$, Warren $P$, Watson GK, Hodgson $R$, Allison C. Methods for microscopic characterization of oral biofilms: analysis of colonization, microstructure, and molecular transport phenomena. Adv 
Dent Res 1997:11:133-149.

24. Zero DT, Fu J, Anne KM, Cassata S, McCormack SM, Gwinner LM. An improved intra-oral enamel demineralization test model for the study of dental caries. J Dent Res 1992;71:871-878.

25. Sanchez AY, de Oliveira CL, Negrini TC, Hashizume LN, Hara AT, Maltz $M$, Arthur RA. In situ effect of arginine-containing dentifrice on plaque composition and on enamel demineralization under distinct cariogenic conditions. Caries Res 2018; 52:588-597.
26. Carlsson J, Egelberg J. Effect of diet on early plaque formation in man. Odontol Revy 1965; 16:112-125.

27. Schilling KM, Bowen WH. Glucans synthesized in situ in experimental salivary pellicle function as specific binding sites for Streptococcus mutans. Infect Immun 1992;60: 284-295

Received June 28, 2018 Accepted August 17, 2018 